\title{
Dental implications in oral cancer patients
}

\author{
Jaume Escoda-Francolí ${ }^{1}$, Araceli Rodríguez-Rodríguez ${ }^{2}$, Silvia Pérez-García ${ }^{3}$, Jordi Gargallo-Albiol ${ }^{4}$, Cos- \\ me Gay-Escoda ${ }^{5}$
}

${ }^{1}$ DDS. Master in Oral Surgery and Implantology. University of Barcelona Dental School. Investigator of the IDIBELL Institute. Specialist of the Service of Oral surgery and Implantology of the Centro Médico Teknon. Barcelona

${ }^{2}$ DDS. Master in Oral Surgery and Implantology. University of Barcelona Dental School

${ }^{3}$ DDS. Master in Oral Surgery and Implantology. Associate Professor of Oral Surgery. University of Barcelona Dental School. Investigator of the IDIBELL Institute

${ }^{4} \mathrm{DDS}$, PhD. Master in Oral Surgery and Implantology. Professor of the Master in Oral Surgery and Implantology. University of Barcelona Dental School. Investigator of the IDIBELL Institute

${ }^{5} \mathrm{MD}$, DDS, PhD. Chairman of Oral and Maxillofacial Surgery. Director of the Master in Oral Surgery and Implantology. University of Barcelona Dental School. Coordinating investigator of the IDIBELL Institute. Head of the Service of Maxillofacial Surgery, Teknon Medical Center. Barcelona, Spain

Correspondence:

Centro Médico Teknon,

Instituto de Investigación IDIBELL,

C/ Vilana 12

08022 Barcelona (Spain)

cgay@ub.edu

Received: 06/03/2010

Accepted: 06/06/2010
Escoda-Francolí J, Rodríguez-Rodríguez A, Pérez-García S, GargalloAlbiol J, Gay-Escoda C. Dental implications in oral cancer patients. Med Oral Patol Oral Cir Bucal. 2011 Jul 1;16 (4):e508-13.

http://www.medicinaoral.com/medoralfree01/v16i4/medoralv16i4p508.pdf

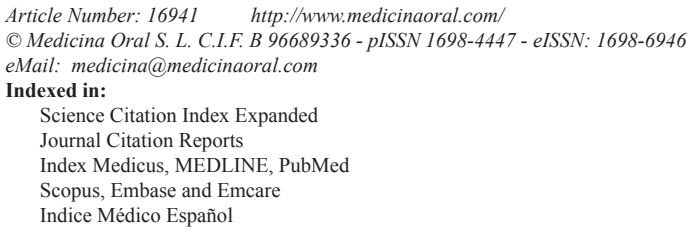

\begin{abstract}
Objectives. A study is made of the dental implications of oral cancer, with a view to avoiding the complications that appear once oncological treatment is started.

Patients and Methods. The study comprised a total of 22 patients diagnosed with oral cancer according to clinical and histological criteria in the Service of Maxillofacial Surgery (Dental Clinic of the University of Barcelona, Spain) during the period 1996-2005, and posteriorly treated in different hospital centers in Barcelona.

Results. Of the 22 patients diagnosed with oral cancer in our Service, the present study finally analyzed the 12 subjects who reported for the dental controls. As regards the remaining 10 patients, 5 had died and 5 could not be located; these subjects were thus excluded from the analysis. All of the smokers had abandoned the habit. The most common tumor location was the lateral margin of the tongue. None of the patients visited the dentist regularly before the diagnosis of oral cancer. T1N0M0 was the most common tumor stage. Surgery was carried out in $50 \%$ of the cases, while $8.4 \%$ of the patients received radiotherapy and $41.6 \%$ underwent surgery with postoperative radiotherapy. In turn, $66.6 \%$ of the patients reported treatment sequelae such as dysgeusia, xerostomia or speech difficulties, and one patient suffered osteoradionecrosis. Forty-one percent of the patients did not undergo regular dental controls after cancer treatment. As regards oral and dental health, $16.6 \%$ presented caries, and 50\% had active periodontal disease.

Conclusions. Protocols are available for preventing the complications of oral cancer treatment, and thus for improving patient quality of life. However, important shortcomings in the application of such protocols on the part of the public health authorities make it difficult to reach these objectives.
\end{abstract}

Key words: Oral cancer, oral complications of oncological treatment, prevention protocol. 


\section{Introduction}

Cancer incidence in humans has gradually increased over the last century. Surgical, radiotherapeutic, chemotherapeutic and biological treatments have experienced important advances, with an important reduction in the morbidity associated with the radical surgical practices of the past.

It is important to diagnose oral cancer in its early stages, since the management of small and localized tumors (T1N0M0) involves less morbidity and mortality than more advanced-stage disease, where treatment must be more aggressive. Indeed, the stage in which the disease is diagnosed is directly correlated to long-term survival (1).

However, in practice many malignancies are diagnosed and treated in advanced stages and/or once the patients have already experienced symptoms causing them to seek medical help. This explains the great interest in improving multidisciplinary therapies, and particularly in establishing more reliable techniques for diagnosing head and neck tumors, with a view to securing detection in the early stages of the disease (2).

The treatment of head and neck cancer is fundamentally based on surgery, radiotherapy, chemotherapy, biological therapy, or any combination of such treatments. In turn, the management of malignant disease usually involves toxic effects upon healthy cells, and this can give rise to serious oral complications (3).

Some of these complications can be significantly reduced by applying strict oral and dental controls and care before, during and after oncological treatment. The lack of a balanced diet, poor oral hygiene, the presence of fractured teeth or defective restorations, periodontal disease or poorly fitting dentures can contribute to the development of local or systemic infections which in turn may prevent the administration of complete antineoplastic therapy, requiring a reduction in dose or delaying the application of therapy (3).

Ideally, oral examination should take place 2-4 weeks before the start of oncological treatment, to allow adequate healing of any lesions caused by dental treatment. The dental surgeon must be aware of all the possible complications of oral cancer treatment, and of the therapeutic options available to deal with them adequately $(2,3)$.

The present study examines the dental implications in oral cancer patients, with a view to avoiding the complications that appear once oncological treatment is started.

\section{Patients and Methods}

A retrospective observational study was made of the patients diagnosed with oral cancer according to clinical and histological criteria in the Service of Maxillofacial Surgery (Dental Clinic of the University of Barcelona, Spain) during the period 1996-2005.
A total of 22 patients were documented, of which 10 were excluded from the analysis (corresponding to 5 deaths and 5 subjects that could not be located). The remaining 12 patients were seen again to collect data relating to the study variables.

The following variables corresponding to each patient were entered in a database: age, gender, toxic habits before and after the diagnosis of oral cancer, lesion location, histological findings and preoperative tumor stage, treatment provided and treatment sequelae, frequency of dental visits before cancer diagnosis and postoperative dental controls - with the assessment of oral and dental health conditions at that time, including the presence of mucosal lesions, periodontal disease and dental caries (CPI and CAOD indexes).

In all cases, oral cancer was diagnosed on the basis of the histological study of the lesions, followed by patient referral to the corresponding hospital center, where the required oncological treatment was provided.

The data were compiled by a single observer, and were processed using the SPSS version 12.0 statistical package (SPSS Inc., Chicago, USA) (license of the University of Barcelona, Spain). The Kolmogorov-Smirnov test with Lilliefors correction was used to assess normal distribution of the quantitative variables. Variables showing a normal distribution were reported as the mean and standard deviation (SD), while the median and interquartile range (IQR) were used in the absence of a normal distribution.

\section{Results}

The study analyzed a total of 12 patients ( 8 males $(67 \%)$ and 4 females (33\%) (Table 1). The mean patient age was 66.5 years (range 45-89). Fifty percent of the patients were smokers, and all of them stopped smoking after the diagnosis of oral cancer. In 6 cases $(50 \%)$, the lesions were located on the lateral margin of the tongue, while three tumors were located in the floor of the mouth $(25 \%)$, one in the palate $(8.3 \%)$, one in the retromolar region $(8.3 \%)$ and one in the lower lip (8.3\%).

In the great majority of the cases the histological study revealed squamous cell carcinoma (11 patients, 91.6\%), with the identification of adenocarcinoma in one patient $(8.3 \%)$. Tumor stage at the time of the diagnosis was T1N0M0 in 8 cases $(66.6 \%)$, TisN0M0 in three cases $(25 \%)$, and T4N0M0 in a single patient (8.3\%). Surgical resection was carried out in 6 cases $(50 \%)$. Two patients received radiotherapy only $(16.6 \%)$, while four were subjected to combination surgical resection plus radiotherapy (33.3\%). In two of these latter subjects graftbased reconstructive surgery was carried out, since a hemimandibular resection had been performed in one case, and a hemimaxillectomy in the other.

A total of 6 subjects received radiotherapy either alone or in combination with surgery, and only one of these 
Table 1. Study variables in the 12 patients evaluated.

\begin{tabular}{|c|c|c|c|c|c|c|}
\hline Patient & Location & Histology & Stage & Treatment & $\begin{array}{l}\text { Treatment prior to } \\
\text { oncological therapy }\end{array}$ & $\begin{array}{l}\text { Postoperative } \\
\text { dental control }\end{array}$ \\
\hline 1 & $\begin{array}{l}\text { Lateral margin of } \\
\text { the tongue }\end{array}$ & $\begin{array}{l}\text { Squamous cell } \\
\text { carcinoma }\end{array}$ & $\mathrm{T}_{1} \mathrm{~N}_{0} \mathrm{M}_{0}$ & Surgery & No & No \\
\hline 2 & $\begin{array}{c}\text { Floor of the } \\
\text { mouth }\end{array}$ & $\begin{array}{l}\text { Squamous cell } \\
\text { carcinoma }\end{array}$ & $\mathrm{T}_{1} \mathrm{~N}_{0} \mathrm{M}_{0}$ & $\begin{array}{l}\text { Surgery plus } \\
\text { preoperative } \\
\text { radiotherapy }\end{array}$ & No & No \\
\hline 3 & $\begin{array}{c}\text { Floor of the } \\
\text { mouth }\end{array}$ & $\begin{array}{l}\text { Squamous cell } \\
\text { carcinoma }\end{array}$ & $\mathrm{T}_{4} \mathrm{~N}_{0} \mathrm{M}_{0}$ & $\begin{array}{l}\text { Surgery plus } \\
\text { postperative } \\
\text { radiotherapy }\end{array}$ & No & No \\
\hline 4 & $\begin{array}{l}\text { Lateral margin of } \\
\text { the tongue }\end{array}$ & $\begin{array}{c}\text { In situ } \\
\text { carcinoma }\end{array}$ & $\mathrm{T}_{\mathrm{is}} \mathrm{N}_{\mathrm{O}} \mathrm{M}_{0}$ & Surgery & No & Yes \\
\hline 5 & $\begin{array}{c}\begin{array}{c}\text { Floor of the } \\
\text { mouth }\end{array} \\
\end{array}$ & $\begin{array}{l}\text { Squamous cell } \\
\text { carcinoma }\end{array}$ & $\mathrm{T}_{1} \mathrm{~N}_{0} \mathrm{M}_{0}$ & Surgery & No & No \\
\hline 6 & $\begin{array}{l}\text { Lateral margin of } \\
\text { the tongue }\end{array}$ & $\begin{array}{l}\text { Squamous cell } \\
\text { carcinoma }\end{array}$ & $\mathrm{T}_{1} \mathrm{~N}_{0} \mathrm{M}_{0}$ & Radiotherapy & Yes & Yes \\
\hline 7 & $\begin{array}{l}\text { Lateral margin of } \\
\text { the tongue }\end{array}$ & $\begin{array}{l}\text { Squamous cell } \\
\text { carcinoma }\end{array}$ & $\mathrm{T}_{1} \mathrm{~N}_{0} \mathrm{M}_{0}$ & Surgery & No & Yes \\
\hline 8 & $\begin{array}{l}\text { Lower vestibular } \\
\text { gums }\end{array}$ & $\begin{array}{c}\text { In situ } \\
\text { carcinoma }\end{array}$ & $\mathrm{T}_{\mathrm{is}} \mathrm{N}_{\mathrm{O}} \mathrm{M}_{0}$ & $\begin{array}{l}\text { Surgery plus } \\
\text { postperative } \\
\text { radiotherapy }\end{array}$ & No & Yes \\
\hline 9 & $\begin{array}{l}\text { Lateral margin of } \\
\text { the tongue }\end{array}$ & $\begin{array}{c}\text { In situ } \\
\text { carcinoma }\end{array}$ & $\mathrm{T}_{\mathrm{is}} \mathrm{N}_{\mathrm{O}} \mathrm{M}_{0}$ & Surgery & No & Yes \\
\hline 10 & Palate & $\begin{array}{l}\text { Adenocarci- } \\
\text { noma }\end{array}$ & $\mathrm{T}_{1} \mathrm{~N}_{0} \mathrm{M}_{0}$ & $\begin{array}{l}\text { Surgery plus } \\
\text { postperative } \\
\text { radiotherapy }\end{array}$ & No & Yes \\
\hline 11 & Lower lip & $\begin{array}{l}\text { Squamous cell } \\
\text { carcinoma }\end{array}$ & $\mathrm{T}_{1} \mathrm{~N}_{0} \mathrm{M}_{0}$ & Radiotherapy & No & Yes \\
\hline 12 & $\begin{array}{l}\text { Lateral margin of } \\
\text { the tongue }\end{array}$ & $\begin{array}{l}\text { Squamous cell } \\
\text { carcinoma }\end{array}$ & $\mathrm{T}_{1} \mathrm{~N}_{0} \mathrm{M}_{0}$ & Surgery & No & Yes \\
\hline
\end{tabular}

subjects $(16.6 \%)$ underwent dental treatment before radiotherapy. A prosthesis was prepared in this case to protect the irradiated oral tissues, with the adoption of oral hygiene measures and conservative management of the dental caries.

None of the patients regularly visited the dentist for the routine control of oral and dental health during oncological treatment. Dental visits were only recorded in the event of acute conditions in which the patients reported to the emergency service.

As regards patient follow-up after oncological treatment, 8 subjects $(67 \%)$ were controlled by their primary care dentist or private dentist and maxillofacial surgeon, while the remaining four patients (33\%) were seen only by the maxillofacial surgeon.

The following treatment complications were recorded: speech difficulties in 5 cases (41.6\%), xerostomia in four cases $(33.3 \%)$ (though of milder intensity than at the start of oncological treatment), hypogeusia in three patients $(25 \%)$, and osteoradionecrosis in one case $(8.3 \%)$. This latter condition was successfully treated with antibiotics, and the patient is presently asymptomatic.

As regards oral and dental health at the time of the control made during the study, 6 patients had active periodontal disease (50\%), and two presented caries (16.6\%).
Evaluation of the soft tissues in turn revealed reticular lichen planus in three patients (25\%), diagnosed on the basis of the clinical and histological findings.

The mean time from the diagnosis of oral cancer to study data collection was 4.5 years (range 1-9 years).

\section{Discussion}

Oral and dental care in oral cancer patients should begin when the lesion is detected and the diagnosis is established. Planning includes prior evaluation, patient preparation, the measures to be applied after oncological treatment, and long-term follow-up. In our series, only one patient was referred to the general dentist for the prevention of oral complications of radiotherapy. However, after oncological treatment the number of patients controlled by the dentist was seen to increase (4).

The oral complications of radiotherapy or chemotherapy may manifest immediately or at a later stage in chronic form (5).

The potential immediate complications include mucositis. This is characterized by oral soft tissue inflammation, and is seen in $40 \%$ of all patients administered chemotherapy (6), and in $80-100 \%$ of those subjected to radiotherapy. Mucositis manifests as ulcerated and burning lesions between 7-10 days after the start of on- 
cological treatment. While these lesions are transient, they greatly affect patient wellbeing - causing pain, burning sensation, dry oral mucosal membranes, overinfections and difficulties for maintaining adequate oral hygiene or eating (7).

The treatment of mucositis is fundamentally preventive and palliative. The main objectives are to afford pain relief and prevent the appearance of secondary infections. Many substances have been used to lessen the severity of mucositis. However, absolute efficacy has not been established for any of them. Such substances include the following: cytokines (granulocyte-macrophage colony-stimulating factor or GM-CSF), sucralfate, vitamins $A$ and D, prostaglandins (PGE-1, PGE-2), immune modulators (immunoglobulins, indomethacin, pentoxifylline), amino acids (glutamine), cytoprotectors (aminophosphine) and hormones (melatonin) (8). Lin et al. carried out a study to determine the effect of zinc upon mucositis. The authors concluded that the administration of zinc supplements in radiotherapy-based oncological treatments can lessen the severity of mucositis and dermatitis (9).

In patients subjected to high-dose chemotherapy, other investigators have reported that prophylaxis based on oral rinses with GM-CSF does not lessen the severity of mucositis (10). At present, no method has received widespread acceptance for the prevention of mucositis (11). Pain control in mucositis can be achieved with topical local anesthetics, benzidamine, doxepin (12) or morphine or other opioid drugs (13). Mucositis was not evaluated in our series, since data collection corresponded to late follow-up after initial oncological treatment.

Patients subjected to radiotherapy or chemotherapy may suffer neutropenia, which in turn increases the risk of serious infections. This complication requires antibiotic treatment for prolonged periods of time, thus potentially giving rise to alterations in oral flora and producing an environment favorable to the growth of opportunistic microorganisms. In this context, $80 \%$ of all patients subjected to such treatments develop fungal infections, fundamentally produced by Candida albicans. The most common infections include viral agents such as Herpes simplex, Herpes zoster and Epstein-Barr virus. All of them give rise to clinical manifestations in the form of multiple ulcerations that cause eating difficulties. Such patients may also experience worsening or exacerbation of periapical and periodontal bacterial infections that were already present before treatment, and which can lead to serious systemic complications. This explains the importance of ensuring the absence of oral and dental infectious disease before starting oncological treatment (14).

Alterations in salivary gland function are also frequent complications of radiotherapy. Such alterations are observed in over $50 \%$ of all post-irradiation patients (15).
In this context, xerostomia produces dry mouth, burning sensation, changes in the tongue surface (depapillation, reddening), cracked lips, eating difficulties and problems wearing dentures. Pathogenic modification of the oral flora can also occur, and the risk of dental caries increases (16). Xerostomia appears early from the second week after the start of radiotherapy, and may prove irreversible (17). In our series, $33.3 \%$ of the irradiated patients experienced xerostomia, though to a lesser degree than at the end of oncological treatment.

Symptomatic treatment of post-irradiation xerostomia in patients without residual salivary function is based on saliva substitutes such as carboxymethylcellulose, sorbitol, xylitol, etc. (18). However, these products offer no significant beneficial effects, and many patients prefer to swallow sips of water repeatedly as a lubricating measure (19). Patients with preserved residual salivary function can be treated with salivary stimulants such as pilocarpine, neostigmine, nicotinic acid, etc. (20). Fox et al., in a double-blind, placebo-controlled study of 39 patients with post-irradiation xerostomia, found $94.8 \%$ of the subjects to experience improvement after one month of treatment with $5 \mathrm{mg}$ of pilocarpine three times a day - this improvement being maintained for 6 months after the end of radiotherapy (21). Many studies have shown that intensity-modulated radiotherapy contributes to improve salivary gland preservation (17,22-25).

Dysgeusia induced by radiotherapy is conditioned by a series of factors: direct neurotoxic action upon the taste receptor cells, xerostomia and possible overinfections. Most patients recover within 2-3 months, though in some cases permanent hypogeusia may result (14). Twenty-five percent of our patients reported subjective permanently lessened taste sensation.

Thrombocytopenia and/or coagulation disorders induced by chemotherapy can give rise to bleeding. Consequently, in the presence of active periodontal disease during chemotherapy, the patient may bleed spontaneously, or hemorrhage may result from only minimal gingival trauma. Petechiae may also be observed, most often located on the lips, soft palate or floor of the mouth (8).

Late complications or the exacerbation of acute conditions may occur. These include particularly fibrosis and atrophy of the mucosal membranes, caries (typically rampant and very destructive) preferentially located in the region of the dental neck, dysgeusia and muscle fibrosis - giving rise to important limitations in mandibular movement (16).

Osteoradionecrosis is the least frequent but also the most important late complication. It is characterized by aseptic necrosis of irradiated bone, with the loss of regenerative capacity of the osteogenic tissue. The mucosa becomes friable and weak, thus favoring the appearance of lesions that fail to heal and which appear spontane- 
ously or secondary to only minor traumatisms. The diagnosis of osteoradionecrosis is based on the clinical manifestations such as ulceration or necrosis of the oral mucosa over a period of more than three months, together with the data provided by the panoramic X-ray study, which reveals irregular radiotransparencies with areas of abnormal radiopacity indicating the presence of bone sequestration. In our series only one patient with T1N0M0 cancer located in the floor of the mouth and subjected to radiotherapy before surgery developed osteoradionecrosis. This case was treated with analgesics and antibiotics, and the patient is presently free of symptoms.

We agree with other authors that the diagnosis and treatment of oral cancer requires a multidisciplinary approach, including the intervention of a dental surgeon. Unfortunately, most oncological teams do not contemplate the valuable contribution of the dentist in such patients. The oral cavity is often neglected in the evaluation and planning of head and neck cancer therapy. As a result, no adequate measures are taken referred to the complications that may appear in any structure of the stomatognathic apparatus $(14,16,26)$. This situation is particularly worrisome in pediatric oncological patients in which the late effects of cancer treatment upon dental and maxillary development are frequently not taken into account (27).

\section{Conclusion}

Protocols for preventing the oral and dental complications of oral cancer treatment aim to improve patient quality of life. However, as has been seen in the present study, important shortcomings in the application of such protocols make it difficult to reach this objective.

\section{References}

References with links to Crossref - DOI

1. Onizawa K, Nishihara K, Yamagata K, Yusa H, Yanagawa T, Yoshida H. Factors associated with diagnostic delay of oral squamous cell carcinoma. Oral Oncol. 2003;39:781-8.

2. Miller M, Kearney N. Oral care for patients with cancer: a review of the literature. Cancer Nurs. 2001;24:241-54.

3. López-Galindo MP, Bagán JV, Jiménez-Soriano Y, Alpiste F, Camps C. Clinical evaluation of dental and periodontal status in a group of oncological patients before chemotherapy. Med Oral Patol Oral Cir Bucal. 2006;11:E17-21.

4. Scully C, Epstein JB. Oral health care for the cancer patient. Eur J Cancer B Oral Oncol. 1996;32B:281-92.

5. Wright WE, Haller JM, Harlow SA, Pizzo PA. An oral disease prevention program for patients receiving radiation and chemotherapy. J Am Dent Assoc. 1985;110:43-7.

6. Malik IA, Moid I, Haq S, Sabih M. A double-blind, placebo-controlled, randomized trial to evaluate the role of tetrachlorodecaoxide in the management of chemotherapy-induced oral mucositis. J Pain Symptom Manage. 1997;14:82-7.

7. Meirovitz A, Kuten M, Billan S, Abdah-Bortnyak R, Sharon A, Peretz T, et al. Cytokines levels, severity of acute mucositis and the need of PEG tube installation during chemo-radiation for head and neck cancer-a prospective pilot study. Radiat Oncol. 2010;5:16.
8. Naidu MU, Ramana GV, Rani PU, Mohan IK, Suman A, Roy P. Chemotherapy induced and/or radiation therapy-induced oral mucositis--complicating the treatment of cancer. Neoplasia. 2004;6:42331.

9. Lin LC, Que J, Lin LK, Lin FC. Zinc supplementation to improve mucositis and dermatitis in patients after radiotherapy for head-andneck cancers: a double-blind, randomized study. Int J Radiat Oncol Biol Phys. 2006;65:745-50.

10. Dazzi C, Cariello A, Giovanis P, Monti M, Vertogen B, Leoni M, et al. Prophylaxis with GM-CSF mouthwashes does not reduce frequency and duration of severe oral mucositis in patients with solid tumors undergoing high-dose chemotherapy with autologous peripheral blood stem cell transplantation rescue: a double blind, randomized, placebo-controlled study. Ann Oncol. 2003;14:559-63.

11. Scully C, Epstein J, Sonis S. Oral mucositis: a challenging complication of radiotherapy, chemotherapy, and radiochemotherapy. Part 2: diagnosis and management of mucositis. Head Neck. 2004;26:7784.

12. Epstein JB, Epstein JD, Epstein MS, Oien H, Truelove EL. Doxepin rinse for management of mucositis pain in patients with cancer: one week follow-up of topical therapy. Spec Care Dentist. 2008;28:73-7.

13. Krajnik M, Zylicz Z, Finlay I, Luczak J, Van Sorge AA. Potential uses of topical opioids in palliative care--report of 6 cases. Pain. 1999;80:121-5.

14. Wiseman M. The treatment of oral problems in the palliative patient. J Can Dent Assoc. 2006;72:453-8.

15. Davies AN, Broadley K, Beighton D. Xerostomia in patients with advanced cancer. J Pain Symptom Manage. 2001;22:820-5.

16. Kielbassa AM, Hinkelbein W, Hellwig E, Meyer-Lückel H. Radiation-related damage to dentition. Lancet Oncol. 2006;7:326-35.

17. Jabbari S, Kim HM, Feng M, Lin A, Tsien C, Elshaikh M, et al. Matched case-control study of quality of life and xerostomia after intensity-modulated radiotherapy or standard radiotherapy for head-and-neck cancer: initial report. Int J Radiat Oncol Biol Phys. 2005;63:725-31.

18. Ship JA, McCutcheon JA, Spivakovsky S, Kerr AR. Safety and effectiveness of topical dry mouth products containing olive oil, betaine, and xylitol in reducing xerostomia for polypharmacy-induced dry mouth. J Oral Rehabil. 2007;34:724-32.

19. Guchelaar HJ, Vermes A, Meerwaldt JH. Radiation-induced xerostomia: pathophysiology, clinical course and supportive treatment. Support Care Cancer. 1997;5:281-8.

20. Fox PC, Van der Ven PF, Baum BJ, Mandel ID. Pilocarpine for the treatment of xerostomia associated with salivary gland dysfunction. Oral Surg Oral Med Oral Pathol. 1986;61:243-8.

21. Fox PC, Atkinson JC, Macynski AA, Wolff A, Kung DS, Valdez $\mathrm{IH}$, et al. Pilocarpine treatment of salivary gland hypofunction and dry mouth (xerostomia). Arch Intern Med. 1991;151:1149-52.

22. Münter MW, Karger CP, Hoffner SG, Hof H, Thilmann C, Rudat $\mathrm{V}$, et al. Evaluation of salivary gland function after treatment of head-and-neck tumors with intensity-modulated radiotherapy by quantitative pertechnetate scintigraphy. Int J Radiat Oncol Biol Phys. 2004;58:175-84.

23. Meirovitz A, Murdoch-Kinch CA, Schipper M, Pan C, Eisbruch A. Grading xerostomia by physicians or by patients after intensitymodulated radiotherapy of head-and-neck cancer. Int J Radiat Oncol Biol Phys. 2006;66:445-53.

24. Nishimura Y, Nakamatsu K, Shibata T, Kanamori S, Koike R, Okumura M, et al. Importance of the initial volume of parotid glands in xerostomia for patients with head and neck cancers treated with IMRT. Jpn J Clin Oncol. 2005;35:375-9.

25. Parliament MB, Scrimger RA, Anderson SG, Kurien EC, Thompson HK, Field GC, et al. Preservation of oral health-related quality of life and salivary flow rates after inverse-planned intensity- modulated radiotherapy (IMRT) for head-and-neck cancer. Int J Radiat Oncol Biol Phys. 2004;58:663-73.

26. Sciubba JJ, Goldenberg D. Oral complications of radiotherapy. Lancet Oncol. 2006;7:175-83. 
27. Avşar A, Elli M, Darka O, Pinarli G. Long-term effects of chemotherapy on caries formation, dental development, and salivary factors in childhood cancer survivors. Oral Surg Oral Med Oral Pathol Oral Radiol Endod. 2007;104:781-9.

\section{Acknowledgements}

This study has been carried out by the consolidated research group in "Dental and Maxillofacial Pathology and Treatment" of the Institut d'Investigació Biomèdica de Bellvitge (IDIBELL), with financial support from the oral surgery teaching-healthcare agreement among the University of Barcelona, the Consorci Sanitari Integral and the Servei Català de la Salut of the Generalitat de Catalunya. 